\title{
Schiff Base of Metal Complex Derived from Glycine and Benzaldehyde
}

\author{
Ishaq Yahaya Lawan ${ }^{1}$, Mohammed Muftahu Beli ${ }^{1}$, Mohammed Adamu ${ }^{1}$, \\ Fatima Baba Isah ${ }^{2}$ and Maryam Abubakar ${ }^{3}$ \\ ${ }^{1}$ Department of Chemistry, Nigerian Army University Biu, Borno, Nigeria \\ ${ }^{2}$ Department of Chemical Sciences, Federal Polytechnic, Bida, Nigeria \\ ${ }^{3}$ Department of Chemistry, Kano University of Science and Technology, Wudil, Nigeria
}

\begin{abstract}
Schiff base ligand derived from glycine and benzaldehyde was synthesized together with its metal complexes (zinc and cobalt). The solubility, IR analysis and conductivity measurement were carried out. Antibacterial activities were evaluated using welldiffusion method. The bacterial assay was carried out on two pyogenic bacteria $E$. coli and Staphylococci and the results showed that the complexes have high antibacterial activity.
\end{abstract}

\section{Introduction}

A condensation process, in which the nucleophilic nitrogen atom of amine, attack on the electrophilic carbon atoms of aldehydes and ketones. In end product, the $\mathrm{C}=\mathrm{O}$ group is replaced by a $\mathrm{C}=\mathrm{N}$ group. This product is known as Schiff base/imine/azomethine group/anils. Schiff base, named after Hugo Schiff, is a compound and the general structure of Schiff base is $\mathrm{R}_{2} \mathrm{C}=\mathrm{NR}^{*}$, where $\left[\mathrm{R}^{*} \neq \mathrm{H}\right]$ and $\left[\mathrm{R}^{*}=\right.$ alkyl or aryl group], $[\mathrm{R}=$ May be $\mathrm{H}]$.

The Schiff base ligand in which N, O-donor atoms are present act as monodentate, bidentate and chelate/bridging agent with metal ions. The Schiff base ligand and its iron complexes were screened in vitro for their antibacterial, antifungal, antitoxic and anticancer activity.

Received: September 20, 2019; Revised: December 20, 2019; Accepted: March 3, 2020

Keywords and phrases: Schiff base, glycine, benzaldehyde, E. coli, pyogenese, metal complexes.

Copyright (C) 2020 Ishaq Yahaya Lawan et al. This is an open access article distributed under the Creative Commons Attribution License, which permits unrestricted use, distribution, and reproduction in any medium, provided the original work is properly cited. 
Metal complexes of Schiff bases have played a fundamental role in the advancement of co-ordination chemistry. Schiff bases present adaptable and supple sites of ligands proficient to attach with a variety of metal ions to offer complexes with appropriate properties for hypothetical and practical applications. Metal chelates of $\mathrm{N}$ and $\mathrm{S}$ chelating ligands have concerned significant consideration because of their remarkable physicochemical properties and prominent biological activities. The $\mathrm{N}$ and $\mathrm{S}$ atoms perform a crucial role in the coordination of metals in several metal biomolecules. The Schiff bases (containing azomethine linkage) are found to be most appropriate ligand by many researchers for the coordination complexes due to its notable ability of coordination through $\mathrm{N}$ and $\mathrm{S}$ atoms (sometimes oxygen also). By the donation of lone pair of electrons of Schiff base, the hybridization of vacant orbital of metal occurs and coordination complex is formed. Some significant transition metals also demonstrate micro nutrient properties and participate in essential biological functions in animal and plant kingdom. Extensive research on these complexes has revealed significant evolution in utilization of metal complexes as drugs to treat numerous human diseases like carcinomas, lymphomas, infection control, anti-inflammatory, diabetes and neurological disorders. Moreover Schiff base complexes have also been extensively considered for electrochemical [1], thermodynamic studies [2]. The metal complexes containing heterocyclic like thiazole are found to be component of many pharmacologically and biologically active compounds. For instance compounds containing benzothiazole and sulphonamide derivatives were reported to be antifungal [3-4], anti-inflammatory [5], anti-HIV [6], anti-cancer [7], anti-carbonic anhydrase [8], [9] and in therapeutic fields. In the present review attempts have been made to describe the wide applications of Schiff bases and their complexes in various imperative fields.

Zayed et al. [10] were prepared SB by the condensation of bisaldehyde (2,2'(ethane1,2-diylbis(oxy))dibenzaldehyde, hydrazine carbothioamide and the metal complexes by iron chloride, the organic ligand. They analyzed by elemental, magnetic measurements, electronic, IR, 1H-NMR, mass spectra, Molar conductance, Magnetic susceptibility, TG, DTG, DTA. Both show high antibacterial activity for Gram-positive than Gram-negative bacteria. Adly et al. [11] have synthesized, the Schiff base was prepared by AHTD, ethylenediamine and the metal salt, lithium hydroxide, SB ligand was mixed to synthesize metal complexes and Magdy Shebl [12] have synthesized the Schiff base by o-acetoacetyl-phenol,1,2-diaminopropane and isatin. Reactions of the ligand with $\mathrm{FeCl}_{3} \cdot 6 \mathrm{H}_{2} \mathrm{O}$ salts were formed complexes. They characterized by elemental, spectral (IR, 
UV-Vis, 1H NMR, ESR and mass), magnetic and molar conductance. Fe (III) complexes were showed high activity towards S. aureus, E. coli.

Rahman et al. [13] have synthesized iron complex containing the Schiff base were prepared by the 5-bromo-2-hydroxybenzlaldehyde, amino acid (L-alanine, Lphenylalanine, L-aspartic acid, L-histidine, L-arginine) solution and complexes were synthesized by SB ligand and $\mathrm{FeSO}_{4} \cdot\left(\mathrm{NH}_{4}\right)_{2} \mathrm{SO}_{4} \cdot 6 \mathrm{H}_{2} \mathrm{O}$ and determined by elemental, IR, UV-Visible, conductivity, magnetic susceptibility, the stoichiometry and screened for antibacterial activity against E. coli, P. aeruginosa and B. cereus.

Abdel-Rahman et al. have synthesized the metal complexes of Schiff base ligands from the 2-hydroxy-1-naphthaldehyde in [14] and 5-bromosalicylaldehyde in [15], the amino acid (ala, phala, aspa, his or arg) solution. The metal complexes prepared by ligand and $\mathrm{FeSO}_{4} \cdot\left(\mathrm{NH}_{4}\right)_{2} \mathrm{SO}_{4} \cdot 6 \mathrm{H}_{2} \mathrm{O}$ and characterized via elemental, thermo gravimetric analysis, molar conductance, IR, electronic, mass spectra and the stability constant. They were screened for antibacterial against E. coli, $P$. aeruginosa, B. cereus and $P$. purpurogenum, A. flavus and T. roseum (fungus).

$\mathrm{Fe}$ (II) complexes with N-(2-hydroxyethyl)-5-nitrosalicylaldimine was synthesized by Selma Celen et al. [16]. The tridentate Schiff base was prepared by 2-hydroxy-5nitrobenzaldehyde, ethanolamine and identified by elemental, UV-vis, IR, NMR spectra. The antimicrobial activities of ligand and metal complex were evaluated against $C$. jejuni, E. aerogenes, E. coli, L. monocytogenes, $P$. aeruginosa, $P$. vulgaris, $S$. aureus, $S$. marcescens, S. sonnei, K. pneumoniae, C. albicans, A. flavus, A. niger, P. expansum, $P$. lanosum and A. alternata [16].

Khan et al. [17] were prepared Schiff base by the condensation of 4-dimethylaminobenzaldehyde and 4-aminobenzoic acid and complex were identified by UV/Vis, FTIR, NMR, Mass Spectra, XRD, TGA, SEM and screened antibacterial activity against $P$. aeruginosa, K. pneumoniae, E. coli, antifungal; A. flavus, A. fumigatus, A. niger, F. solani and anti-leishmanial; Leishmania major, L. tropica and L. donovani.

Schiff bases derived from an amino and carbonyl compound are an important class of ligands that coordinate to metal ions via azomethine nitrogen and have been studied extensively [18]. In azomethine derivatives, the $\mathrm{C}=\mathrm{N}$ linkage is essential for biological activity, several azomethines were reported to possess remarkable antibacterial, antifungal, anticancer and diuretic activities [19]. Schiff bases have wide applications in 
food industry, dye industry, analytical chemistry, catalysis, fungicidal, agrochemical and biological activities [20]. With the increasing incidence of deep mycosis, there has been increasing emphasis on the screening of new and more effective antimicrobial drugs with low toxicity. Schiff base complexes are considered to be among the most important stereo chemical models in main group and transition metal coordination chemistry due to their preparative accessibility and structural variety [21]. A considerable number of Schiff base complexes have potential biological interest, being used as more or less successful models of biological compounds [22]. Not only have they played a seminal role in the development of modern coordination chemistry, but also they can also be found at key points in the development of inorganic biochemistry, catalysis and optical materials [23].

\section{Material and Method}

All the chemicals, reagent and apparatus used in this work were of analytical grade and were washed with detergent, rinsed out and dried before used. All weighing were carried out on electric weighing balance. All the chemicals (solvent and reagents) were of analytical grade and used without further purification.

\section{Materials and reagents}

Beakers, Measuring cylinder, Conical flask, Reflux set, Analytical balance, Melting point apparatus, Thermometer, Capillary tube, IR-spectrophotometer, Reagent bottle, Magnetic stirrer, Test tube, Ethanol, Acetones, Chloroform, DMSO, Benzene, n-hexane, Methanol, Distilled water.

\section{Synthesis of Schiff base ligand}

Synthesis of Schiff base from glycine and benzaldehyde procedure: the Schiff base formed from glycine and benzaldehyde was prepared by adding $20 \mathrm{ml}$ of ethanol to glycine $(1 \mathrm{~g})$ in a clean beaker, this is followed by addition of $(1.26 \mathrm{~g})$ benzaldehyde. The resulting was filtered washed with distilled water and methanol and dried in desiccator.

\section{Preparation of cobalt complex}

The cobalt chloride was prepared by adding $20 \mathrm{ml}$ of ethanol to the cobalt chloride $(2.314 \mathrm{~g})$ in a clean beakers, this is then reacted with solution of prepared Schiff base 
$(0.01 \mathrm{~mol})$. And the reaction mixture was refluxed for three hours; the resulting was filtered washed with distilled water and methanol and dried in desiccators.

\section{Preparation of zinc complex}

The zinc nitrate complex was prepared by adding $20 \mathrm{ml}$ of ethanol to zinc nitrate $(0.01 \mathrm{~mol})$ in a clean beaker, this is then reacted with a solution of prepared Schiff base $(0.02 \mathrm{~mol})$. And the resulting was filtered washed with distilled water and methanol and dried in desiccator.

\section{Solubility test of the complexes}

The metals complexes and their Schiff base were tested for their solubility. About (5ml) of each complexes was transferred into a test tube to which about $2 \mathrm{ml}$ of the corresponding solvent was added and the solubility was observed and recorded. The results obtained are shown in Table 1 .

\section{Melting point of complexes}

The melting point of Schiff base and the complexes was determined by introducing a pinch of each into a capillary tube and then inserted into the melting point apparatus. The readings of the temperature at which the complexes and the Schiff base melt were recorded. The reading was taken using a $360^{\circ} \mathrm{C}$ glass thermometer. The results obtained are shown in Table 2.

\section{Infrared Spectrophotometer}

The IR spectra of the metal complexes and the Schiff base was carried out using the spectrophotometer machine, after its lens was cleared and properly cleaned with a drop of an acetone using cotton wool, $0.1 \mathrm{~g}$ of each compound was placed on the lens and result obtained were recorded. It is shown in Table 3.

\section{Anti-Bacterial Studies}

The antibacterial activity was carried out by an adapted agar well-diffusion method. The antibacterial activity of the synthesized compounds was determined against (Staphylococcus pyogenic and E. coli) microbial stain. A volume of $10 \mathrm{ml}$ of each tested compounds was distributed directly in the solid medium presided with microbial in 
columns. They were incubated for $24 \mathrm{hrs}$ at $37^{\circ} \mathrm{C}$. The antimicrobial activity was done by measuring the growth inhibitor zone using ruler. The results obtained were recorded and are shown in Table 4.

\section{Conductivity Measurement}

The conductivity test was determined by the dissolving $0.5 \mathrm{~g}$ of the complexes each in $5 \mathrm{~cm}^{3}$ methanol. The conductivity was standardized with 0.01 moldm ${ }^{-3}$ solution to conductance of $1413 \mu \mathrm{Scm}^{-1}$. The conductivity meter cell was then inserted into the solution of the complex the result obtained were recorded.

\section{Result and Discussion}

The complexes described in chapter two were analyzed using solubility test, melting point, infrared spectral analysis. Biological activities test, and conductivity measurement and the results obtained are discussed in this chapter.

\section{Solubility test}

The solubility of the complexes and the Schiff base in different solvent were determined and recorded in the table below.

Table 1. Solubility test.

\begin{tabular}{|l|l|l|l|l|}
\hline S/N & Solvent & Cobalt chloride & Zinc nitrate & Schiff base \\
\hline 1 & Acetone & S & SS & S \\
\hline 2 & n-Hexane & IS & S & S \\
\hline 3 & Chloroform & SS & S & S \\
\hline 4 & Methanol & SS & SS & IS \\
\hline 5 & DMSO & S & S & S \\
\hline 6 & Ethanol & S & S & S \\
\hline 7 & Benzene & SS & SS & S \\
\hline 8 & Water & S & S & S \\
\hline
\end{tabular}

KEY: $\mathrm{S}=$ soluble, $\mathrm{IS}=$ insoluble, $\mathrm{SS}=$ slightly soluble. 
Table 2. Melting and colour of the complexes.

\begin{tabular}{|l|l|l|}
\hline Complexes & Melting point $\left({ }^{\circ} \mathrm{C}\right)$ & Colour \\
\hline Cobalt & 250 & Purple \\
\hline Zinc & 260 & White \\
\hline Schiff base & 210 & Milky \\
\hline
\end{tabular}

Table 3. Infrared spectral data of complexes.

\begin{tabular}{|l|l|l|l|l|l|}
\hline & $\mathrm{V}(\mathrm{C}=\mathrm{N})$ & $\mathrm{V}(\mathrm{N}-\mathrm{C})$ & $\mathrm{V}(\mathrm{C}=\mathrm{O})$ & $\mathrm{V}(\mathrm{O}-\mathrm{H})$ & $\mathrm{V}(\mathrm{C}-\mathrm{O}) \mathrm{cm}^{3}$ \\
\hline Schiff base & 2140 & 1134 & 1700 & - & 1112 \\
Cobalt Complex & 2166 & 1112 & 1626 & 3477 & 1220 \\
Zinc complex & - & 1136 & 1655 & 3469 & 1041 \\
\hline
\end{tabular}

Table 4. Bacterial activity.

\begin{tabular}{|c|c|c|c|c|c|c|}
\hline \multicolumn{4}{|c|}{ Staphylococcus } & \multicolumn{3}{|c|}{ E. coli } \\
\hline & $1000(\mu \mathrm{g} / \mathrm{ml})$ & 2000 & 3000 & 1000 & 2000 & 3000 \\
\hline Ligands & - & ++ & - & - & + & ++ \\
\hline Cobalt & & & & & & \\
\hline chloride & +++ & +++ & +++ & +++ & +++ & - \\
\hline Zinc & & & & & & \\
\hline nitrate & - & - & - & - & +++ & - \\
\hline
\end{tabular}

Key

Inactive

- (inhibition Zone $<6-9 \mathrm{~mm}$ )

Slightly active $\quad+\quad$ (inhibition zone $>6-12 \mathrm{~mm}$ )

Moderately active $\quad++$ (inhibition zone $>9-12 \mathrm{~mm}$ )

High $\quad+++($ inhibition zone $>12 \mathrm{~mm}$ ).

\section{Discussion}

The ligand was obtained as milky crystalline solid and the melting point of the ligand was found to be $210^{\circ} \mathrm{C}$ while that of the complexes was $250-260^{\circ} \mathrm{C}$ respectively for zinc and cobalt. 
The solubility test carried out on the Schiff base and the complexes in some organic solvent showed that they are soluble only in DMSO but slightly soluble methanol, benzene, and soluble in water.

The result of the IR spectra of the Schiff base and its metal complexes shows the sharp absorption in functional group and finger print region, the absorption band.

The anti-bacterial activity of Schiff base and metal complexes against Staphylococcus, pyogenic and E. coli showed a very high respond in the complexes than the Schiff base. In which the inhibition zone of the complex where high this shows that the complexes have high anti-bacterial activity.

\section{Conclusion}

The Schiff base derived from glycine and benzeldehyde was successfully synthesized. The Schiff base metal (ii) complexes were synthesis by the reaction of prepared Schiff base with metal complexes. The complex was found to be soluble in only DMSO and slightly soluble in some organic solvents. The microbial studies of the complexes and ligand reveal that the complexes have high antibacterial activities. The IR spectrum concluded that the ligand behave as bidentate ligand, (coordinated in all the complexes).

Schiff base and its complexes have a lot of applications like clinical, analytical, pharmacological, biological properties against microorganisms. The Schiff bases and its metal complexes are playing an important role in pharmacological field in form of drug because the biological activity results indicate that Schiff base and metal complexes show activity against for many bacteria such as $E$. coli and pyogenic bacteria, fungi etc.

\section{References}

[1] Feng Guo, Thermodecomposition kinetics of $\mathrm{La}(\mathrm{III})$ complex with Schiff base ligand derived from glycine and O-vanillin, Asian J. Chem. 20(4) (2008), 2962-2968.

[2] Feng Guo, Zhen Jia, B. L. Wen, M. L. Yu and L. Z. Xiu, Electrochemical characteristics of a $\mathrm{Cu}$ (II) Schiff base complex and its interaction with DNA, Asian J. Chem. 20(3) (2008), 1692-1696.

[3] A. A. Chavan and N. R. Pai, Synthesis and biological activity of N-substituted-3-chloro-2 azetidinones, Molecules 12 (2007), 2467-2477. https://doi.org/10.3390/12112467 
[4] Sushilkumar S. Bahekar and Devanand B. Shinde, Synthesis and anti-inflammatory activity of [2-(Benzothiazol-2-ylimino)-4-oxo-3-phenylthiazolidin-5-yl]-acetic acid derivatives, J. Korean Chem. Soc. 47 (2003), 237-240.

https://doi.org/10.5012/jkcs.2003.47.3.237

[5] L. Racane, V. Tralic-Kulenovic, L. Fiser-Jakic, D. W. Boykin and G. Karminski-Zamola, Synthesis of bis-substituted amidinobenzothiazoles as potential anti-HIV agents, Heterocyclic 55 (2001), 2085-2098. https://doi.org/10.3987/COM-01-9305

[6] I. Caleta, M. Grdisa, D. Mrvos-Sermek, M. Cetina, V. Tralic-Kulenovic, K. Pavelic and G. Karminski-Zamola, Synthesis, crystal structure and antiproliferative evaluation of some new substituted benzothiazoles and styrylbenzothiazoles, Farmaco 59 (2004), 297305. https://doi.org/10.1016/j.farmac.2004.01.008

[7] C. T. Supuran and A. Scozzafava, Carbonic anhydrase and their therapeutic potentials, Exp. Opin. Ther. Pat. 10 (2000), 575-600. https://doi.org/10.1517/13543776.10.5.575

[8] Mahmood Ul-Hasan, Zahid H. Chohan, Andrea Scozzafava and Claudiu T. Supuran, Carbonic anhydrase inhibitors: Schiff's bases of aromatic and heterocyclic sulfonamides and their metal complexes, J. Enzyme Inhibition \& Medicinal Chemistry 19(3) (2004), 263-267. https://doi.org/10.1080/14756360410001689595

[9] M. A. Neelakantan, M. Esakkiammal, S. S. Mariappan, J. Dharmaraja and T. Jeyakumar, Synthesis, characterization and biocidal activities of some Schiff base metal complexes, Indian J. Pharm. Sci. 72(2) (2010), 216-222. https://doi.org/10.4103/0250-474X.65015

[10] Ehab M. Zayed et al., Thermal and spectroscopic investigation of novel Schiff base, its metal complexes, and their biological activities, Journal of Thermal Analysis and Colorimetry 116 (2014), 391-400. https://doi.org/10.1007/s10973-013-3560-y

[11] Omima M. I. Adly et al., Synthesis, spectral characterization, molecular modeling and antimicrobial activity of new potentially $\mathrm{N}_{2} \mathrm{O}_{2}$ Schiff base complexes, Journal of Molecular Structure 1054-1055 (2013), 239-250.

https://doi.org/10.1016/j.molstruc.2013.09.037

[12] Magdy Shebl, Synthesis, spectroscopic characterization and antimicrobial activity of binuclear metal complexes of a new asymmetrical Schiff base ligand: DNA binding affinity of copper(II) complexes, Spectrochimica Acta Part A: Molecular and Biomolecular Pectroscopy 117 (2014), 127-137.

https://doi.org/10.1016/j.saa.2013.07.107

[13] Laila H. Abdel-Rahman et al., DNA binding ability mode, spectroscopic studies, hydrophobicity, and in vitro antibacterial evaluation of some new Fe(II) complexes 
bearing ONO donors amino acid Schiff bases, Arabian Journal of Chemistry 10 (2017), S1835-S1846. https://doi.org/10.1016/j.arabjc.2013.07.010

[14] Laila H. Abdel-Rahman et al., Design, characterization, teratogenicity testing, antibacterial, antifungal and DNA interaction of few high spin Fe(II) Schiff base amino acid complexes, Spectrochimica Acta Part A: Molecular and Bio Molecular Spectroscopy 111 (2013), 266-276. https://doi.org/10.1016/j.saa.2013.03.061

[15] Laila H. Abdel-Rahman et al., Metal based pharmacologically active agents: Synthesis, structural characterization, molecular modeling, CT-DNA binding studies and in vitro antimicrobial screening of iron(II) bromosalicylidene amino acid chelates, Spectrochimica Acta Part A: Molecular and Biomolecular Spectroscopy 117 (2014), 366-378. https://doi.org/10.1016/j.saa.2013.07.056

[16] Selma Celen et al., Synthesis, spectroscopic characterization, and antimicrobial activities of $\mathrm{Ni}$ (II) and $\mathrm{Fe}$ (II) complexes with $N$-(2-hydroxyethyl)-5-nitrosalicylaldimine, Journal of Coordination Chemistry 66 (2013), 3170-3181.

https://doi.org/10.1080/00958972.2013.829568

[17] M. I. Khan et al., Spectral, XRD, SEM and biological properties of new mononuclear Schiff base transition metal complexes, Inorganic Chemistry Communications 35 (2013), 104-109. https://doi.org/10.1016/j.inoche.2013.06.014

[18] P. A. Vigato and S. Tamburini, Coord. Chem. Rev. 248 (2004), 1717. https://doi.org/10.1016/j.cct.2003.09.003

[19] C. T. Barboiu, M. Luca, C. Pop, E. Brewster and M. E. Dinculescu, Eur. J. Med. Chem. 31 (1996), 597.

[20] (a) S. Gaur, Asian J. Chem. 15(1) (2003), 250. (b) M. J. Genin, C. Biles, B. J. Keiser, S. M. Poppe, S. M. Swaney, W. G. Tarpley, Y. Yage and D. L. Romero, J. Med. Chem. 43(5) (2000), 1034. https://doi.org/10.1021/jm990383f

[21] H. Keypour, M. Rezaeivala, L. Valencia, P. Perez-Lourido and H. Reza Khavasi, Synthesis and characterization of some new $\mathrm{Co}(\mathrm{II})$ and $\mathrm{Cd}(\mathrm{II})$ macroacyclic Schiff-base complexes containing piperazine moiety, Polyhedron 28 (2009), 3755. https://doi.org/10.1016/j.poly.2009.08.021

[22] K. S. Suslick and T. J. Reinert, The synthetic analogs of O2-binding heme proteins, $J$. Chem. Educ. 62 (1985), 974. https://doi.org/10.1021/ed062p974

[23] F. Tisato, F. Refosco and G. Bandoli, Structural survey of technetium complexes, Coord. Chem. Rev. 135-136 (1994), 325-397. https://doi.org/10.1016/0010-8545(94)80072-3 